\title{
Forma da dor e dor da forma: significado e função da dor física entre praticantes de bodybuilding em academias de musculação do Rio de Janeiro
}

\author{
| ${ }^{1}$ Cesar Sabino, ${ }^{2}$ Madel T. Luz |
}

Resumo: Buscamos destacar os sentidos e significados que a dor representa para os praticantes de fisiculturismo nas academias da cidade do Rio de Janeiro. Foram investigadas oito academias entre as zonas norte e sul da cidade no período de 12 meses (2008-2009), utilizando observações participantes, etnográficas e entrevistas abertas, além dos dados coletados em pesquisa de período anterior. A construção do corpo neste grupo está relacionada a organização e administração da intensidade e dos tipos de dor percebidos e interpretados pelos atletas ou praticantes assíduos, fato associado aos rituais de instituição que constroem a pessoa do bodybuilder. A dor corpórea é, portanto, não apenas parâmetro para a construção eficaz da forma, mas item fundamental para a demarcação hierárquica de papéis e de identidade daqueles que fazem parte da fração dominante no campo da musculação. É também, para alguns indivíduos, uma estratégia para superar o sofrimento.

> Palavras-chave: dor; sofrimento; musculação; bodybuilding; antropologia do corpo.
1 Departamento de Estudos Políticos, Universidade Federal do Estado do Rio de Janeiro. Rio de Janeiro-RJ, Brasil. Endereço eletrônico: cesarsabino@ hotmail.com

2 Universidade Federal Fluminense e Universidade Federal do Rio Grande do Sul. Niterói-RJ e Porto Alegre-RS, Brasil. Endereço eletrônico: madelluz@uol.com.br 
Este trabalho analisa dados coletados em pesquisa qualitativa, incluindo atividades de campo etnográfico (observaçōes diretas e participantes), entrevistas abertas e conversas com informantes em academias de musculação (bodybuilding) e fitness da cidade do Rio de Janeiro. Com esta análise, visamos a destacar sentido(s) representado(s) pela dor corpórea na construção da pessoa do fisiculturista. Além do material coletado nas academias de musculação e fitness em diferentes regiōes da cidade ( 2 academias no Méier, 1 em Copacabana, 2 em Botafogo, 2 no Grajaú e 1 em Jardim América), foram também usados dados de observações de trabalhos anteriores em outros bairros (SABINO, 2000, 2004; SABINO; LUZ, 2007) nos quais a mesma metodologia foi utilizada.

Objeto difícil de ser classificado, e variável de acordo com as culturas e os indivíduos pela "subjetividade" implícita, a dor foi negligenciada durante séculos pela própria medicina, a ponto de até hoje profissionais da área de saúde terem dificuldade em lidar com o sofrimento dos pacientes. Destarte, na medicina hipocrática e galênica, a dor era concebida como um sintoma inevitável a ser observado para o estabelecimento do diagnóstico. Com o desenvolvimento dos analgésicos e anestesias, cirurgias e antibióticos, um programa médico foi construído visando tratar a dor por seu aspecto objetivo. Aspecto que se relaciona com o modelo societário moderno (LUZ, 1988; ORTEGA, 2008), no qual o conforto passou a ter papel fundamental na organização da vida cotidiana e na economia (VINCENT, 1992).

O médico John Bonica, na década de 50, escreveu um livro denominado The management of pain, no qual definiu de forma geral a dor em psicossomática ou sem lesão, e dor crônica - oposta à dor aguda - definida como toda dor que dura de três a seis meses e resiste ao tratamento habitual. Da mesma forma, o médico Ronald Melzack concebeu uma teoria na qual a dor não mais era vista como apenas um sinal de alarme, mas como um sistema de regulação natural, podendo ser descrita como variando em intensidade e em qualidade, de acordo com numerosos elementos psicológicos e fisiológicos (MEYRAN, 2005). Embora este processo específico de classificação e objetivação da dor tenha ocorrido no mundo científico, mormente o da medicina, há também a dimensão social da mesma - coletiva ou pessoal, não apenas o aspecto biopsicológico -, que ocorre no contexto cultural. Neste aspecto, o eu (self) 
apresentaria a tendência a funcionar como espelho psíquico, refletindo por

sua vez os aspectos dos outros selfs ou das coisas aos quais estaria afetiva e permanentemente ligado, o que de certa forma demandaria interpretação sistêmica das relações sociais (NASIO, 2008; CSORDAS, 2008; ORTEGA, 2008; LE BRETON, 2009; SABINO; LUZ, 2011).

Sob este prisma, o saber prático dos fisiculturistas também organiza e modula a intensidade da dor, relacionando-a à própria construção dos papéis dos agentes sociais na estrutura do grupo - veremos a seguir -, pois o fisiculturismo não foge à regra das atividades esportivas, ou mesmo das práticas corporais como luta íntima contra o sofrimento, esforço contínuo para transformar a performance num marco no continente da dor (LE BRETON, 1995).

\section{Corpo e palavra}

Sociedades humanas, diferentemente de outras espécies, apresentam sistemas simbólicos constituídos por significantes produtores de significados intermediados pelos sentidos, que por sua vez organizam as práticas e por elas são organizados, formando novamente significantes no processo intermitente da vida material e simbólica (LÉVI-STRAUSS, 2002; DERRIDA, 2006). Em se tratando do sistema simbólico inerente aos grupos sociais das academias de musculação e fitness da cidade do Rio de Janeiro, dor e sacrifício apresentam o valor e o preço a serem pagos pela conquista de uma vitória presumível na necessária construção identitária. Vale salientar que ritos - comportamentos codificados e estáveis - são processos incontornáveis para grupos sociais produzirem e reproduzirem suas características e mesmo as transformarem (TURNER, 1974; DURKHEIM, 1978; TAMBIAH, 1997; PEIRANO, 2001; CLASTRES, 2003; MAUSS; HUBERT, 2005; BOURDIEU, 2008) A “tribo urbana” (MAFFESOLI, 1987) dos fisiculturistas ou "marombeiros", apresenta práticas similares àquelas de um grupo religioso com esquemas rigorosos de comportamentos alimentares, práticas de cuidados corporais, saber específico e esotérico ligado à forma e jargão peculiar em geral de origem inglesa, não raro, estranho para leigos: bodypump, bodyjump, fitness, whey protein, ripped fuel, transport, bodybalance, spinning, humam grouth hormone, Jack 3d, cross training, etc. (BERGER, 2008). É necessário sublinhar que estamos falando de uma fração de frequentadores das academias cariocas e não do grupo inteiro. 
Nosso objeto de observação são os fisiculturistas, parcela mínima e assídua dentro das academias de musculação e fitness, e não todas as pessoas e grupos de praticantes de atividades físicas desses locais. Geralmente participam de competições de bodybulding e são os que amealham saber específico e ascético sobre como construir, através de exercícios, suplementação alimentar, dietas, drogas e fármacos, um corpo adequado à representação de perfeição da forma entre eles. Este saber os leva a se fecharem entre si, conversando sobre os temas que interessam ao grupo e as práticas que o constituem. Conforme Wacquant apontou em seu estudo sobre os gyms de boxe em Chicago, estes grupos parecem se tornar ilhas de ordem e virtude que rechaçam qualquer tipo de tema, comentário ou argumento que não esteja relacionado às práticas de construção da forma física e da aquisição progressiva e ascética dos objetivos prescritos para os treinos (WACQUANT, 2002).

Por outro lado, a ausência de comunicação entre essas pessoas e os outros grupos presentes no contexto das academias pode também representar um processo advindo do mundo do trabalho contemporâneo, no qual a "luta pela sobrevivência" demanda disputa constante de poder, seja ele econômico ou simbólico. No contexto pesquisado, apesar de a intensa competição se consolidar, talvez tendo por base os modelos contemporâneos do trabalho no mercado capitalista, ocorre também (mesmo que de forma circunstancial e evanescente) a busca de novos códigos de solidariedade e identificação coletiva que venham situar o indivíduo como pessoa através da construção do sentimento de pertença a algo ou alguém; sentimento que eventualmente aloca o agente em relaçôes ou laços sociais, mesmo frouxos e difusos, mas ainda laços (LUZ, 2003; MATTOS; LUZ, 2009).

Nos dez anos que decorreram desde o início da primeira pesquisa por nós realizada (SABINO, 2000, 2002, 2004) algumas mudanças ocorreram nas academias de musculação e fitness. De prática de classe média, a musculação se expandiu para as classes baixas e para a nova classe média da era Lula; também se consolidou e cresceu a prática do MMA (mixed martial arts) assim com expandiu o número de mulheres praticando lutas, fitness e bodybuilding. Em algumas academias, esse número supera atualmente em muito o de praticantes masculinos. Fora isso, aumentou a "medicamentalização" das práticas, tendo se tornado marcante a influência dos médicos na prescrição de esteroides anabolizantes, anfetaminas e hormônio do crescimento (HGH) em 
seus consultórios particulares, processo que era realizado anteriormente por

leigos praticantes (DUARTE, 1999). Desta forma, também hoje existe uma cadeia crescente de médicos que praticam o que denominam anti-age medicine. Associados às farmácias de manipulação, prescrevem substâncias controladas e mesmo proibidas para fisiculturistas e todos aqueles que querem e têm poder aquisitivo para pagar por seus serviços e indicações terapêuticas. Vale salientar, nesse processo, que os médicos, sob a égide da autoridade, dominaram atualmente parte significativa do "tráfico de bombas" (esteroides anabolizantes) que ocorria - e ainda ocorre - dentro das academias.

É preciso destacar que nas academias de musculação e bodybuilding, dor e sofrimento podem ter diferentes significados ou mesmo significados antagônicos, porém complementares, quando a primeira engendra processos específicos que dão sentido e racionalidade à fragmentação socioeconômica e cultural da sociedade contemporânea. Fragmentação que produz o sofrimento nas pessoas. No bodybuilding

[...] fala-se do corpo, da vida pessoal, dos mecanismos de aceitação, e, principalmente da vida que se desdobra naquele cenário: das dietas, dos suplementos alimentares, dos relógios Polares que são verdadeiras calculadoras ambulantes (calculam passos, batimentos cardíacos, calorias...), do peso, da porcentagem de gordura corporal, de massa gorda versus massa magra, do novo treino puxado indicado pelo instrutor, da dor que se manifesta no corpo [quando, como e de que forma] após o treino, de novos equipamentos para o cultivo do corpo [...] (BERGER, 2008, p. 2, grifo nosso).

A dor, desta forma, pode dar sentido ao sofrimento, sendo também interpretada de acordo com a classe social. Por exemplo, em academias de bairros marcadamente operários, a resistência à mesma é diretamente associada à masculinidade, sendo a prática dos exercícios de musculação entendida como ato de malhar, forçar e mesmo machucar o corpo, fazendo-o moldar-se ao modelo previsto. Esse processo implica também uma performance rústica, composta por gritos, palavrões e arremessos de pesos ao chão após exercícios, e o bulling em relação àqueles que não procedem da mesma forma. Isso significa "malhar" para os frequentadores. Mesmo as mulheres do grupo apresentam, nesses locais, comportamentos similares.

Já em academias mais caras de bairros de classe média e média alta, o comportamento do grupo é em geral pautado pela suposta administração científica da dor por parte dos praticantes que não representam a prática como 
performance rústica, mas como busca calculada e elegante pela formatação do corpo, calcada nos avanços da ciência biomédica. Esse comportamento, visto pelos frequentadores de classe baixa como sendo "comportamento de fresco ou viadinho", não visa escapar da dor, mas adequá-la, conduzi-la de forma racional a propósitos estéticos hierarquizantes e nobres que desprezam o comportamento dos grupos de classe inferior. Neste aspecto, o termo utilizado para as práticas de exercícios é o verbo "treinar", e não o verbo "malhar", utilizado pelos grupos de menor poder aquisitivo. O praticante de classe alta "treina" utilizando todos os recursos tecnológicos possíveis e de última geração para atingir seu objetivo estético, sem compreender a dor como sentimento a ser exposto como justificativa de uma resistência supostamente superior e mesmo máscula.

$\mathrm{O}$ praticante de classe baixa, por sua vez, não apenas expõe suas dores e lesões como troféu, como considera a maioria dos aprimoramentos tecnológicos inúteis e sinais de "frescura" ou gasto desnecessário, haja vista que os elementos comportamentais identitários e positivos aqui são aqueles constitutivos das representações de rusticidade relacionadas ao que é ser "macho de verdade" ou "mulher de fibra". Elementos rebuscados e polidos são tidos como características femininas tradicionais e, portanto, inferiores. A imagem do ogro é um signo de positividade para essa parcela de praticantes das academias de bairros de origem operária.

\section{Dor como positividade}

A demanda de significação face à dor experimentada pela pessoa neste contexto de interação ultrapassa o sofrimento imediato: "compreender o sentido de sua pena é outra maneira de compreender o sentido da vida" (LE BRETON, 1995, p. 107), pois todo grupo social define a legitimidade de suas dores. Naquilo que se refere à construção da pessoa do fisiculturista, a dor não apenas está presente no risco causado pelo uso dos esteroides anabolizantes e similares (SABINO, 2000), mas no próprio cotidiano dos exercícios. O fisiculturista, através da sua prática, aprende a construir um vasto mapa sensorial - um saber corporal e prático - que classifica os tipos de dor alocando-os em mais ou menos danosos, construtivos ou destrutivos, conforme a intensidade e a manifestação da mesma.

A dor no contexto citado está diretamente associada à dedicação aos exercícios ao domínio estóico das açôes e dos desejos. Sendo assim, ela, a dor, é via de superação 
do sofrimento, ao mesmo tempo em que funciona como elemento fundamental para a produção da identidade individual e grupal. A capacidade pessoal de resistência relacionada aos gradativos exercícios com pesos cada vez maiores exige do agente um saber prático ligado ao corpo para evitar lesões graves por esforço repetitivo e hérnias. Portanto, se há na maioria das vezes uma biopolítica na qual o saber médico e as representações sobre a beleza controlam o corpo dos agentes sociais no contexto contemporâneo, reproduzindo o sistema social, há, por outro, um contrapoder, mesmo que eventual e efêmero, produzido por alguns atores e grupos que demonstram a existência de reflexividade específica nos mesmos sistemas sociais e de ação. Reflexividade fundamental para a dinâmica social, mas também para sua mudança ou, no mínimo, projetar linhas de fuga do contexto administrativo burocrático e sistêmico (FOUCAULT, 1984; VEYNE, 2011).

A intensidade da dor sofrida e mesmo o risco de vida ou de perda da saúde realizam um processo ritual de construção identitária que se institucionaliza, conferindo àquele que se submete ao mesmo processo aceitação social crescente. $\mathrm{O}$ uso ritual de anabolizantes e outras substâncias e o sentimento da dor consagram a desigualdade, instituindo-a. Dor e anabolizantes, no campo da musculação ou do fisiculturismo, parecem fazer parte de ritos de passagem ou de instituição que não apenas permitem a transposição dos indivíduos de um papel a outro no grupo (BOURDIEU, 2008), mas também reiteram as características específicas de status, já que a eficácia e o poder daqueles que estão em funções de dominação devem ser constantemente provados através de ações que constituem as representações de poder. $\mathrm{O}$ rito da dor e das drogas delimita a distribuição de autoridade no interior do campo da musculação através do que Lévi-Strauss (1976) denominou eficácia simbólica, ou seja, o poder, que é próprio do rito, de agir sobre a realidade agindo sobre a representação que os indivíduos fazem dessa realidade. Portanto, nas academias, ao adquirir, pari passu, um corpo musculoso, o aspirante a fisiculturista consagrado (ao menos no seu grupo delimitado) vai sendo alçado a um novo papel. Sua identidade - mesmo sendo volátil, visto depender da brevidade da forma - é continuamente construída, e a dor e o risco inscrevem-se como emblemas em seu corpo, moldando em sua carne o perfil musculoso do status diretamente radicado na forma e no saber como construí-la.

Nos casos ritualísticos, quanto mais difíceis são as etapas que um indivíduo atravessa para pertencer a uma instituição e desfrutar seu status, mais valor o 
mesmo the confere (BOURDIEU, 2008; SEGALEN, 2002). Assim, processos sociais como estes, apesar de serem competitivos, permitem aos agentes o acesso a sentidos que conferem significados a suas vidas e à possível competição não solidária que porventura enfrentam em outras dimensões sociais. A existência de distinção das dores ${ }^{2}$ entre os fisiculturistas demonstra um entendimento sensorial do metabolismo muscular que as organiza em boas dores, aquelas que apontam para "um funcionamento construtivo do músculo", entenda-se tal aspecto enquanto crescimento muscular, e dores más, aquelas que apontam para lesões articulares. Portanto, o edema muscular pós-treinamento é o melhor sinal de que os exercícios estão fazendo efeito e são positivos.

Eu "malho" há seis anos e já tô viciado nessa dorzinha aguda que dá dentro do músculo depois de cada treino bom [...] não sei viver sem isso [...] no carnaval, quando viajo fico maluco! Me penduro em árvore pra fazer flexão de braço, fico procurando bujão de gás p’ra levantar [...] agora abriram uma academia lá em Araruama, tomara que funcione nesse carnaval $[\ldots]$ não consigo ficar sem malhar $[\ldots]$ quando paro de sentir o músculo doendo depois dos treinos ou no dia seguinte, começo a ficar doente e deprimido (Gabriel, 22anos, estudante).

Ao contrário da dor positiva, que ocorre após o que chamam "exercícios de qualidade", acionada pelo movimento do grupo muscular treinado, dor que não produz qualquer impedimento à movimentação, há a dor negativa, definida como mais circunscrita a uma determinada região e com intensidade diversa diretamente associada à dificuldade de movimentação daquele grupo muscular, ou mesmo membro. Enquanto a concepção de boa dor está ligada à execução perfeita de exercícios e séries da musculação, a dor prejudicial, ao contrário, é supostamente tida pelos praticantes como fruto de excessos e execuções equivocadas. Assim, basta o diagnóstico - pelo próprio agente - de uma dor de intensidade diferente em local suspeito para que o portador da mesma seja classificado pelos especialistas das academias comunicados - professores ou fisiculturistas mais experientes como propenso a adoecer (sofrer lesão muscular ou de articulação), perdendo parte de seu status e função social, além, consequentemente de parte de sua identidade. Neste aspecto, podemos repetir com Le Breton (1995, p. 108):

[...] todas as sociedades definem implicitamente uma legitimidade da dor que antecipa as circunstâncias sociais, culturais ou psíquicas reputadas penalizáveis. Uma experiência acumulada do grupo conduz seus membros a uma expectativa da dor costumeira imputável a esses acontecimentos... a sociedade indica simbolicamente o limite do lícito, ao realizar tal processo se esforça para dissuadir os possíveis excessos. 
Há entre os fisiculturistas, portanto, uma ritualização da dor que organiza os

sentidos musculares indicadores de avanço ou retrocesso na prática da musculação causada pela conduta considerada correta ou errônea pelos praticantes. Destarte, existem classificações de dores como esferiformes, agudas, pontiagudas, constantes, de movimento ou eventuais, e mesmo prazerosas ou "de fundo" (possivelmente a dor produzida pelo efeito do ácido lático nos músculos exercitados), descrita como levemente aguda e psicologicamente prazerosa, significando eficácia da prática. Quando não há dor, dizem os praticantes e atletas das academias de bodybuiding, é porque os exercícios ministrados não estão surtindo efeito e, por isso, não produzem os resultados esperados: o crescimento da massa muscular e sua definição. Com efeito, mesmo professores de Educação Física são classificados pelos frequentadores como competentes ou incompetentes se prescrevem séries "pesadas" de exercícios e aulas que deixam os alunos doloridos ou não. Se uma série ou aula específica de um profissional da Educação Física não produz algum tipo de dor, é sinal para os alunos que o profissional é incompetente, pois suas aulas são "leves" demais. Os pares de oposição binária: pesado/eficaz, leve/ineficaz, assim como pesado/forte, leve/fraco, formam a estrutura classificatória das dores somáticas dos marombeiros ou fisiculturistas.

Essas classificações remetem ao tradicional e não superado estudo de LéviStrauss sobre as formas da mente humana classificar o mundo. Em $O$ pensamento selvagem (2002), o autor escreve sobre a ciência do concreto que não se contrapõe necessariamente ao conhecimento científico abstrato. Formando sistemas classificatórios calcados em experiências sensoriais e observações da realidade, o pensamento concreto ou selvagem utiliza elementos materiais diversos para ordenar logicamente o universo. Processo denominado bricolagem, ${ }^{3}$ nada deve estruturalmente ao pensamento científico abstrato quando se trata de conferir sentido (ordem) ao mundo e à existência.

Aspectos que se estendem também à alimentação - enjoo, mal-estar, falta de disposição - são tidos como uma espécie de variação desta(s) dor(es) causada(s) pela má conduta, consciente ou não, daquele que é o sofredor desses processos de disfunção fisiológica. A dor negativa e perigosa é aquela que prenuncia a impossibilidade de treinar, aquela que indica bursites, tendinites ou problemas nas articulações dos joelhos, e esse impedimento de treinar, como vimos anteriormente, prejudica a manutenção da identidade do fisiculturista, que 
está relacionada à forma física e depende de intenso treinamento diário para ser mantida. Perder a forma não apenas significa retrocesso e queda de status, mas perda da identificação pessoal e possível despertencimento ao grupo - ou seja, morte social para aquele sistema.

O desempenho muscular radicado na percepção das modulações da dor é, grosso modo, o cerne da busca pela diferenciação em relação a outros grupos e identificação dentro do próprio grupo de fisiculturistas:

[...] a dor, essa dor no fundo do músculo, quer dizer que a malhação tá certa, cara; e depois você sente aquela sensação de leveza depois da adrenalina do exercício... e se você sente isso você tá crescendo, 'cê tá se diferenciando dos inferiores, dos comuns, dos pangarés [...] (Carlos, 24 anos, estudante).

A dor aparece também como a via de ascensão hierárquica e mesmo espiritual, opondo-se diretamente ao sofrimento sinal de derrocada psíquica e física:

[...] é demais sentir cada fibra "arrebentando" quando você tá malhando pesado e depois aquela dorzinha aguda no dia seguinte [...] cada movimento que você faz ela tá lá te lembrando que você tem o dever de continuar, que você deve voltar de novo p'ra academia e fazer outra série mais pesada, mais dolorida, mais radical, cara, p'ra crescer mais e mais e mais [...] É disciplina, e sem disciplina não se chega a lugar nenhum. Sem dor não se ganha nada na vida... é um "vício", se eu não sinto dor no dia seguinte após malhar é porque alguma coisa 'tava errada, é porque a maromba não foi direita, a malhação foi fraca, sem efeito [...] no pain no gain. Essa é a diferença de quem malha sério do resto que não malha... (Pedro, 29 anos, funcionário público).

Esses homens (e mulheres) inscrevem em seus músculos a marca da disciplina rígida traduzida na dor dos exercícios pesados e repetidos durante anos de prática nas academias. $\mathrm{O}$ regozijo da dor, típico de um ascetismo singular, parece significar que na era na qual a busca do prazer tornou-se norma, o sentido da dor também pode ser uma maneira de afirmar a vida e a diferença. Todavia, esse processo reitera a reprodução pela busca incessante do prazer que a sociedade do consumo e do espetáculo engendra. Talvez uma ética ascética (COURTINE, 1995) misturada à outra neorromântica (CAMPBELL, 2001).

Arriscar a vida tomando substâncias tóxicas como esteroides anabolizantes e estimulantes como efedrina ou mesmo a insulina é outro aspecto da apologia ao risco e à dor que sistematiza a identidade do grupo:

Cara eu não sei como te dizer o que sinto [...] posso tentar, sei lá [...] sabe quando tu bota um pega [corrida de carro] e a adrenalina vai a mil? Sabe quando tu tá de moto e tira um fino entre dois caminhões ou faz aquela curva absurda...é isso... esporte 
radical, entende? Tomar bomba, insulina é isso, é um risco, mas dá prazer [...] é o

risco que dá prazer, que é bom [...] tudo que é proibido é bom e o melhor é que além disso tu fica 'sarado', você toma produto, curte e ainda fica bonito, não é o máximo? (Mário, 32 anos, personal trainner e fisiculturista).

Essa combinação, aparentemente comum às sociedades contemporâneas, induz os indivíduos a desejarem extrair sempre mais gozo (em geral sem conseguir prazer) do seu cotidiano, combinando a ética do trabalho protestante-disciplina e ascetismo - ao hedonismo e narcisismo de uma ética do consumo conspícuo. A dor, neste sistema simbólico, está diretamente associada a uma espécie de purificação que poderia ser traduzida pela categoria de "perfectibilidade" (DUARTE, 1999, p. 24). A ideia, inerente ao imaginário ocidental - provavelmente surgida com o movimento iluminista - de que a espécie humana é dotada de uma capacidade de se aperfeiçoar indefinidamente,

[...] de entrar na senda disso que desde então [século XVIII] chamamos de progresso, o desenvolvimento, a transformação ilimitada, a vanguarda - palavras estas fundamentais para nossa cultura, todas elas decorrentes da idéia de que nós somos seres providos de uma capacidade de perfectibilidade constante e indefinida que nos distingue dos demais seres existentes sobre a face da Terra (DUARTE, 1999, p. 24).

Não é novidade que a dor é um instrumento que não apenas regula o sofrimento, mas propicia superação de objetivos; além de ser ferramenta que o corpo acaba construindo para si e em si, e que pode ser utilizada de inúmeras maneiras, como por exemplo, nos casos de doping biológico em atletas olímpicos e paralímpicos. Para aumentar níveis hormonais e alcançar rendimento superior às demais, as atletas femininas da antiga Alemanha Oriental engravidavam, de modo a multiplicar a produção de hemoglobina e abortavam logo depois da competição. Há pouco, nas Paralimpíadas, foi constatado que atletas tetraplégicos induzidos por estímulos dolorosos que eles mesmos provocam quebrando pequenos ossos do corpo, enfiando tachinhas nos pés e cateteres na bexiga até encherem-nas prestes a estourar, conseguem rendimento mais alto que o normal, pois a mensagem de desconforto é enviada pelo nervo periférico para o cérebro, embora não retorne em forma de dor imediata para o membro atacado, produz uma "dor" secundária, pois o sinal desconfortável é enviado para os músculos do coração, gerando aumento da pressão arterial que faz com que o atleta, apesar dos pesares, renda até $10 \%$ mais do que seu adversário. 


\section{Dor e função iniciática no bodybuilding}

Vale salientar que a dor também tem função iniciática, estando presente em todas as chamadas técnicas corporais, e acompanha os ritos de passagem, instaurandose nos indivíduos como memória inscrita na carne e signo de pertencimento a um grupo social específico. Grupos de jovens e adultos das sociedades complexas ocidentais imitam os ritos de passagem das chamadas sociedades simples realizando lacerações na língua, escarificações, piercings, tatuagens, escoriações, queimaduras, suspensões por ganchos cravados na pele, bungee-jump ${ }^{4}$ etc., práticas que podem tomar sentidos diversos das originárias, mas que, da mesma forma, carregam a dor, ou ao menos o temor, em seu bojo, e que sugerem a difusão cultural como função fundamental de manutenção e dinâmica das sociedades. Tanto nos sistemas sociais complexos como nos simples, a experiência da dor e do medo expressa uma mutação ontológica ou passagem de uma dimensão social a outra, de um campo a outro, o que sinaliza a entronização do indivíduo em um estado existencial diverso. A cicatriz ou a experiência momentânea da proximidade da morte traduz o pertencimento a um novo estatuto. Em uma época na qual a virtualidade é a expressão por excelência, relações precárias e passageiras, imagens fugazes e o cotidiano é eivado de experiências turbulentas, a necessidade de atualizar eventualmente uma condição radicada na reconstrução imagética se faz necessária. No caso do bodybuilding, no qual a imagem do corpo musculoso é a própria via de afirmação da identidade, os constantes rituais são necessários e sempre renovados, pois o corpo, fadado inexoravelmente à decadência, sempre foge, de uma maneira ou outra, dos padrões estéticos impostos pelo grupo.

A necessidade do uso de drogas e substâncias diversas especiais (remédios, suplementos alimentares, anfetaminas, hormônio do crescimento) e de variações de intensidade e extensão dos exercícios constrói um cotidiano identitário que necessita ser ritualmente refeito a cada dia e no qual a experiência do dor se faz necessária e inevitável. Os exercícios devem ser realizados até as últimas consequências físicas, provocando dores musculares, para que os resultados sejam atingidos. De fato, se não estiverem acompanhados pela dor, não possuem qualquer eficácia, segundo os praticantes. Sem dor não há progresso; sem dor não há nem mesmo a manutenção do que já foi conquistado; sem dor há apenas decadência. A manifestação ostensiva da mesma, portanto, é motivo de orgulho e honra para os fisiculturistas. Os mais experientes relatam com constância 
suas lesões por esforço repetitivo ou torções nas quais distenderam músculos, arrebentaram ligamentos, obtiveram fraturas por avulsão, necessitando realizar cirurgias. A dor torna mais forte aquele que a atravessa. Como o levantamento de pesos é fundamental para a construção da forma do fisiculturista, uma lesão representa sério risco de dissolução identitária. Portanto, desenvolver a técnica de treinar lesionado é fundamental para esses indivíduos.

Este é um saber prático que não pode ser aprendido em livros. Essa pedagogia implícita é produto da prática em sua mais pura acepção. Não há um modo específico de aprender a treinar lesionado, e como as dores das lesões são constantes e comuns, o aprendizado se realiza com o tempo. Esse fato pode ser aplicado também aos próprios exercícios, que apesar de serem estruturalmente os mesmos infinitamente combinados, sua intensidade e eficácia só é apreendida individualmente na coletividade orquestrada das academias, ou seja, na prática. Assim, como no boxe, ou qualquer outra esporte, não é possível aprender a ser atleta "no papel" (WACQUANT, 2002, p. 121).

Os manuais pouco têm a ensinar de fato àquele que deseja ser um fisiculturista. Um indivíduo pode comprar uma enciclopédia de musculação (a mais famosa e difundida é a de Arnold Schwarzenegger) e todos os pesos e máquinas de exercícios e instalar em sua casa, mas nunca conseguirá se tornar um fisiculturista sem frequentar durante longos anos as academias de musculação, sem se associar ao grupo, sem travar interação, sem passar por todos os rituais necessários para a construção de sua pessoa, pois o saber do grupo se apresenta na ação e só pode ser adquirido efetivamente de forma implícita, prática e coletiva, através da manipulação regulada do corpo, que somatiza e concretiza um saber coletivo detido e exibido pelos membros desta instituição a cada patamar da hierarquia tácita que a atravessa (WACQUANT, 2002). Mais do que se fazer corpo, a sociedade - ou o grupo social - é o corpo desses agentes e por eles feita. $\mathrm{O}$ sentido da dor e da lesão, seu simbolismo e significado precípuo, além das formas e indicações de como tratá-la e continuar cultivando a muscularidade, só são aprendidos no cotidiano das instituições dos “adoradores do ferro". Wacquant, parafraseando Durkheim escreveu que "o gym está para o boxe assim como a igreja está para a religiāo" (2002, p. 120). O mesmo - as academias estão para o bodybuilding de forma similar à Igreja para religião - poderia ser aplicado às academias de musculação. 
Necessário destacar também o estudo de Lopes sobre os dolorosos e arriscados processos de transformação do corpo entre os travestis, demonstrando que esse grupo articula uma lógica simetricamente invertida àquela do fisiculturista ou bodybuilder (embora a função da dor seja a mesma), enquanto um se esforça dolorosamente, fazendo uso de vários tipos de substâncias e técnicas para construir e apresentar, por intermédio dos músculos, hipermasculinidade, a construção da pessoa do (a) travesti implica processo similar, visando à construção da hiperfeminilidade e à perda ao máximo das características masculinas.

A autora relata um estudo de caso do processo de transformação corporal de um homossexual, a "bichinha-boy Alan", que se transforma no travesti Elisa Star. Descreve a dor e os distúrbios do seu informante diante das incontáveis aplicações e ingestão contínua de hormônio feminino (cartelas inteiras de pílulas anticoncepcionais de uma só vez), injeções de silicone com agulhas para uso veterinário e a dor de carregar durante quarenta dias um pedaço de cabo de vassoura atado ao peito com um barbante para evitar que o silicone aplicado não passasse de um lado para o outro. Apesar de todo o ritual de iniciação, a satisfação e o gozo de Alan-Elisa foi grande com sua nova identidade social, com a nova pessoa que passou a ser, testemunhando "a coragem de levar esse sonho a sério" (LOPES, 1995, p. 254).

A experiência da dor pode conferir sentido e mesmo significado à existência e ao mundo, incitando o ser humano a organizar sua realidade ao lhe permitir vislumbrar a dimensão peculiar que simultaneamente nega e afirma tal existência: a morte. Ela - a dor - é inerente à vida como contraponto que confere sua plena medida ao fervor de existir em contraposição ao morrer (LE BRETON, 1995; 2009; BATAILLE, 2014). Em consonância com tal pensamento podemos perguntar:

Haverá na dor experimentada algo comparável ao prazer da repentina melhora? Muito mais bela é a saúde depois da enfermidade [...] Dizem os estóicos que os vícios são úteis, pois valorizam a virtude; com maior razão pode-se dizer que a natureza nos deu o sofrimento a fim de realçar a excelência do prazer e da tranquilidade (MONTAIGNE, 1980, p. 490).

A sócio-lógica presente na experiência da dor funciona de forma similar. Assim como o ritual da tragédia grega afirmava a existência humana e, portanto, o social, exaltando o paradoxo, e por vezes o absurdo (LESKY, 1976; NIETZSCHE, 2004), de modo parecido, a visão do efêmero inscrito nas superfícies dos corpos e das práticas pode demonstrar a profundidade do enigma denominado "ser 
humano" em sua condição de esperançoso sofredor. As palavras de Nietzsche, da

mesma forma que as de Montaigne, podem sintetizar este processo coletivo de modulação, controle e administração da dor:

[...] o homem, o animal mais corajoso e mais habituado ao sofrimento, não nega em si o sofrer, ele o deseja, ele o procura inclusive, desde que lhe seja mostrado um sentido, um para quê no sofrimento. A falta de sentido do sofrer, não o sofrer, era a maldição que até então se estendia sobre a humanidade - e o ideal ascético lhe ofereceu um sentido! (1988, p. 184, grifos do autor).

Os sentidos corporais, por meio das apreensões concretas da experiência, sincronizadas com a capacidade intelectual do ser humano, podem ordenar o mundo. Considerados pelo racionalismo moderno a via do erro, uma sociologia dos sentidos corporais pode sugerir de que forma os mesmos contribuem como instrumentos de classificação e ordenamento da realidade, bases do pensamento concreto fundado na percepção direta do mundo corporificado. O corpo, longe de ser produto inerte de uma sociedade hipostasiada, é ele mesmo a própria sociedade em ação (CSORDAS, 2008; LE BRETON, 2009; BATAILLE, 2014).

\section{Sacrifício, conquista e transformação}

O treinamento do fisiculturismo é um ritual que visa à manutenção e ao aprimoramento da forma, um ritual que exige sacrifício de si e, portanto, risco e dor. Conforme Mauss e Hubert sugeriram (2005), o ritual do sacrifício é o ato de sacralizar, conferindo sentido àquilo que não tem sentido; ao misterioso e ao inefável (PEIRANO, 2001). O sacrifício confere sentido à própria existência social por intermédio de suas instituições. O grupo que estudamos apresenta um aspecto individual, relacionado ao conceito de sujeito, funcionando, contudo, como ritual de passagem ou de instituição produzido pela coletividade, função na qual a dor modulada por intermédio de um saber prático ordena o mundo tanto pelos sentidos corporais como pela razão, contribuindo assim para a construção do papel e da identificação do agente no sistema social, mantendo a unidade do grupo com suas hierarquias específicas. Destarte, a dor deve ser entendida como fato objetivo, de certa maneira independente da subjetividade daquele que a sofre, sinal de alerta que deve servir para a gestão coletiva das formas musculosas, espécie de discurso com lógica própria que deve ser lido eficazmente por aquele que quer ser bem-sucedido na construção do que é considerada a excelência da sua forma física. 
Ao submeter seu corpo à dor, é como se o bodybuilder sacrificasse sua própria carne aos deuses da estética contemporânea. Um dos objetivos é encarnar, buscando copiar as práticas e as formas das figuras dos grandes ícones do panteão mítico - midiático da boa forma física. Espelhando-se nas celebridades das competições esportivas e do fitness, os praticantes reproduzem as regras e a lógica hierárquica típica do grupo (SABINO, 2012). A mesma sugere uma ética da forma que concebe a musculosidade e a ausência de adiposidade como elementos de excelência de caráter. Na pele, nos músculos e no corpo está inscrita (sob o ponto de vista dessas pessoas) a excelência daquele que se concebe livre ao se perceber como senhor de sua forma sem computar o preço pago (não raro tacitamente) à obediência a normas, valores, hierarquias, regras, tradições e instituiçôes do grupo do qual faz parte e que o molda - e que pelo agente é moldado simultaneamente - segundo seus objetivos e funções delimitadas. A relação com o corpo é antes de tudo a relação com os significados que lhes são inerentes (LE BRETON, 2010).

\section{Ritos de suspensão}

Escrevemos aqui, no entanto, sobre um grupo, uma coletividade, ou seja, uma generalidade abstrata. E não podemos esquecer que existem diferenças concretas. Se o todo parece funcionar da forma que tentamos descrever, há sempre o indecidível, o particular, o singular, o reflexivo, a linha de fuga que pode vir a modificá-lo. Para alguns agentes a dor é um elemento manipulável, articulada em reflexividade modulada, efeito da administração e do autodomínio. Via para se tornar (mesmo que momentaneamente), senhor de si, de forma similar a um empreendimento estóico; contudo, sem aquela intensa reflexividade (FOUCAULT, 2012). Agentes que destoam da maioria, utilizando os elementos do sistema que os submete como efeito da condição estrutural. Neste aspecto, a inventividade de alguns atores pode abrir novas possibilidades para o próprio sistema se renovar. Não se trata aqui de retornar a uma sociologia individualista, calcada na ação apenas, mas de tentar expandir uma explicação sintética já presente nos últimos escritos de Bourdieu (2001), por exemplo.

Talvez a partir mesmo da diferença infinitesimal ou molecular (de determinados agentes e/ou pequenos grupos), a dinâmica do sistema social se articule por meio do pensamento e da própria criatividade prática desses atores 
(coletivos ou não) diante dos problemas que lhes são colocados pela estrutura social. As possíveis soluções elaboradas e os contrapoderes assim articulados podem ser difundidos pelas esferas dos sistemas sociais - o que Mauss denominou "imitação prestigiosa" (1974), ou Hannerz chamou de fluxo, ou mesmo, a "rebeliāo contagiosa de algum elemento" (TARDE, 2008, p. 30), transformando (como um bricoleur) as estruturas dos mesmos sistemas a partir dos seus próprios itens ou de outros sistemas. Sob esse prisma, o ascetismo, por exemplo, pode ser encarado de diversas formas que não aquela apenas condescendente com os saberes dominantes (FOUCAULT, 1984). Podem se manifestar em forma de contrapoder, possibilitando o surgimento de novos sentidos e significados dentro do próprio sistema a partir dos elementos dele constitutivos (LUZ, 2003); linha de fuga estratégica ou recusa a se enquadrar inteiramente nos modelos dominantes; cuidado de si que não se dobra plenamente às ordens sociais. Vale ressaltar que sempre há a possibilidade de movimentos moleculares prontos a colocar o socius, a molaridade, em desequilíbrio, pois se o poder está em toda parte; em toda parte pode ser dobrado e redobrado, subvertido, reagido e pensado:

\footnotetext{
[...] o sujeito não é constituinte, ele é constituído [...] mas não deixa por isso de ser livre para reagir, graças a sua liberdade, e de tomar distância, graças ao pensamento. O dispositivo é menos um limite imposto à iniciativa dos sujeitos do que o obstáculo contra o qual ela se manifesta (FOUCAULT, 2008, p. 216).
}

Neste ritmo, podemos tentar reinterpretar a análise que faz Deleuze em relação à literatura de Masoch sobre aspectos da dor e do sofrimento, buscando extrair dessa visão algo que sociologicamente nos auxilie a compreender a relação dos fisiculturistas com a dor. Primeiro, seria necessário separar, apenas esquematicamente, dor e sofrimento. De forma similar como o sacrifício para Mauss é um contrato, subsumido à troca e à dádiva, a relação do masoquista com quem o "domina” também é relação contratual podendo expressar acordo e reflexividade entre os agentes. Nessa relação, o "dominado" não seria alguém que simplesmente ama se destruir, mas quem constrói um regime administrativo do seu próprio desejo, permitindo-se manipular as intensidades da dor em contraposição a uma dor maior e mais inclassificável, a do sofrimento, adiando assim, o prazer:

[...] o prazer interrompe o desejo, de modo que a constituição do desejo como processo deve conjurar o prazer e postergá-lo até o infinito [...] onda retardada de dor, que ele utiliza, não para dela extrair prazer [...] e sim para remontar-lhe o curso e 

suspense como plenitude, como intensidade física e espiritual [em] ritos de suspensão (DELEUZE, 2008, p. 64, grifo nosso).

Esse rito de suspensão, ao deslocar a tríade lógica (externo ou fora/indefinido, suspenso/ separado e dentro/absorvido) presente nos rituais (TURNER, 1974; VAN GENNEP, 2011), estende a mesma suspensão para uma condição indizível, ou trágica, ou seja, sem síntese hegeliana, pois a administração da dor jamais soluciona a existência do sofrimento. A suspensão se manifesta como devir, fluxo, linha de fuga, alertando que a identidade (seja ela qual for) está eternamente em construção em luta perdida contra a inevitável dissolução e transformação em outras identidades. O controle do fluxo da dor, por vezes inflingindo-a a si mesmo, é uma forma de suportar ou burlar o sofrimento. Tentativa de controlar um universo simbólico que escapa (LE BRETON, 2010), buscando conferir significado ao mundo.

A eterna construção do corpo pelo fisiculturista, ao menos em parte e por alguns, pode ser (contrariamente ao que se presume na totalidade das observações superficiais) um contraponto ao modelo platônico pela busca de um ideal, se tornando processo imanente e ininterrupto de suspensão do modelo, invertendo mesmo a lógica do sistema que busca impor um padrão estético a todos os corpos. É uma dobra no mesmo sistema feita pelo agente dentro do sistema - contra o sistema, já que dele não se sai. Portanto, uma reflexividade prática de administrar a dor visando suportar a dor maior do sofrer, dos afetos penosos. O ordenamento da dor ao menos faz esquecer por um tempo o sofrimento e as crises vividas nas sociedades contemporâneas. A sensação dolorosa se contrapõe, nesse caso, à emoção dolorosa, conferindo àquele que domina seu corpo, que o testa, que o leva aos limites, um sentimento circunstancial de liberdade ou autonomia em um habitus ou corporeidade subversora das forças do habitus geral (WACQUANT, 2002; CSORDAS, 2008; LE BRETON, 2010). Nesse aspecto, não apenas o ascetismo se torna um meio de contrapoder, mas também a combinação da musculação com práticas alternativas (mormente yoga e acupuntura, mesmo a medicina chinesa, além de práticas mais "artísticas” como dança de salão), forma um horizonte em constante mutação nas academias de musculação e fitness. Horizonte que não necessariamente se enquadra em todas as suas manifestações como pensamos nas primeiras observações de campo (SABINO; LUZ, 2007) -, 
nos padrões biomecânicos e alienantes de uma sociedade, não raro consumista e

desencantada, mas que também pode sugerir em determinados momentos novas relações de solidariedade (WEBER, 1995; LUZ, 2003; PIERUCCI, 2003).

Nas observações mais recentes realizadas em academias das zonas norte e sul da cidade do Rio de Janeiro, percebemos a formação de grupos de encontros semanais fora das mesmas visando a práticas ao ar livre de tai chi chuan ou yoga, organização de passeios eventuais (sem o compromisso com treinos ou competições), lanches, encontros noturnos ou vespertinos para dançar, subvertendo o modelo individualista, autocentrado e antissocial comum às salas de musculação das academias cariocas. Essas práticas convivem simultaneamente nas mesmas organizaçōes, demonstrando a capacidade reflexiva e, portanto, de possível mudança e adequação de determinadas esferas sociais diante dos problemas que se lhes apresentam.

\section{Considerações finais}

Percebemos que a manipulação da dor por fisiculturistas não significa uma tácita ignorância da realidade que os cerca, nem necessariamente adequação aos modelos estéticos dominantes sem qualquer tipo de reflexividade ou crítica. Se por um lado os rituais de construção da forma envolvem forte adequação às práticas sociais ascéticas e condicionantes moldando o corpo a um tipo específico de ser, é por intermédio deles que ressignificaçôes são produzidas, interferindo no próprio contexto dessas práticas. Esse processo é construído por intermédio da administração do corpo, principalmente da dor, que ao ser manipulado, classificado, controlado, conhecido e reconhecido organiza parte do universo bodybuilder fornecendo um saber prático para as pessoas lidarem e suportarem o sofrimento simbólico presente em seus cotidianos. Esse movimento é realizado como se fosse um contrato do fisiculturista com ele mesmo e com o grupo por intermédio de rituais nos quais o elemento de suspensão é justamente o agenciamento da dor contra o sofrimento e, talvez, a falta de sentido da vida produzida por relações sistêmicas antissolidárias.

A dor autoinfligida é o oposto da falta de sentido e do sofrimento; ela é produção de significados e compromisso por parte de alguns elementos do grupo em restaurar a sociabilidade. Longe de ser autodestruição ou "alienação" do corpo pelo sistema, essa dor é um veículo de autoconhecimento e disciplina oposta àquela 
da sociedade disciplinar construtora da biopolítica, embora ela mesma produto dessas relações de poder. Se no aspecto geral podemos dizer que a maioria segue os ditames da disciplina biopolítica que equaliza o existir num desencantamento geral de consumo conspícuo, é por meio da dor específica aqui tratada, que permite ao que sofre juntar os pedaços de seu mundo numa bricolagem carnal e sensível, que ele se autorrepresenta num processo de individuação no qual a agressão voltada para si mesmo é controlada, diferente do sofrimento.

A dor controlada é a prova da existência reiterada de si mesmo e de sua singularidade e diferença num grupo específico; é a restauração do sentimento do real numa sociedade que, com frequência, vem apresentando sentidos planos e sem profundidade que visam diluir em imagens estereotipadas a própria singularidade da qual necessita para existir. Sendo assim, a força coletiva dobrada e redobrada em seu corpo, pelo controle de sua própria dor, pela potencialização de seus limites e pela autossuperação em busca de resistir ao sofrimento, leva ao menos alguns bodybuilders a nos lembrar da recomendação estoica de Sêneca: ${ }^{5}$

[...] que o homem [...] somente olhe para si mesmo, que confie em seu espírito e esteja preparado para aquilo que o destino lhe envie, isto é, que seja o próprio artífice de sua vida. (SÊNECA, 2010, p. 102, grifo nosso).

\section{Referências}

BATAILLE, G. O erotismo. Belo Horizonte: Autêntica, 2014.

BERGER, M. Rituais corporais contemporâneos. Pontourbe. Revista de Antropologia Urbana da USP. São Paulo, v. 2, n. 1, fev. 2008. Disponível em: http://n-a-u.org/pontourbe02/ Berger2. Acesso em: 13 ago. 2011.

BOURDIEU, P. Economia das trocas linguisticas. São Paulo: Edusp, 2008. . Meditaçôes pascalianas. São Paulo: Bertrand, 2001.

CAMPBELL, C. A ética romântica e o espírito do consumismo moderno. Rio de Janeiro: Rocco, 2001.

CLASTRES, P. Da tortura nas sociedades primitivas. In: CLASTRES, P. A sociedade contra o Estado. São Paulo: Cosac Naify, 2003. p. 195-206.

COURTINE, J.J. Os stakhanovistas do narcisismo: bodybuilding e puritanismo ostentatório na cultura americana do corpo. In: SANT’ ANNA, D. Políticas do corpo. São Paulo: Estação Liberdade, 1995. p. 81-114.

DERRIDA, J. Gramatologia. São Paulo: Perspectiva, 1999. 
DUARTE, L.F.D. O império dos sentidos. In: HEILBORN, M.L. (org.). Sexualidade: o olhar das ciências sociais. Rio de Janeiro: Jorge Zahar, 1999.

DURKHEIM, E. As formas elementares da vida religiosa. São Paulo: Abril Cultural, 1978 (Col. Os Pensadores).

FOUCAULT, M. Ética, sexualidade, política. Ditos e escritos. v. V. Rio de Janeiro: Forense Universitária, 2012.

. História da sexualidade. O cuidado de si. v. 3. Rio de Janeiro: Graal, 1984.

LE BRETON, D. Anthropologie de la douleur . Paris: Éditions Metaillé, 1995.

LESKY, A. Tragédia grega. São Paulo: Perspectiva, 1976.

LÉVI-STRAUSS, C. O desdobramento da representação nas artes da Ásia e da América. In: . Antropologia Estrutural. Rio de Janeiro: Tempo Brasileiro 1976. p. 279-305.

LOPES, S.H.S.S. Corpo, metamorfose e identidade. In: LEAL, O.F. (org.). Corpo e significado. Porto Alegre: EdUFRGS, 1995. p. 113-128.

LUZ, M.T. Novos saberes e práticas em saúde coletiva. São Paulo: Hucitec, 2003.

MAFFESOLI, M. No fundo das aparências. Petrópolis: Vozes, 1995.

. O tempo das tribos. Rio de Janeiro: Forense Universitária, 1987.

MARX, K.; ENGELS, F. A ideologia alemã. São Paulo: Hucitec, 1986.

MATTOS, R.; LUZ, M.T. Sobrevivendo ao estigma da gordura: um estudo socioantropológico sobre obesidade. Physis. Revista de Saúde Coletiva. Rio de Janeiro, v. 19, n. 2, p. 489-507, 2009.

MAUSS, M.; HUBERT, H. Sobre o sacrificio. São Paulo: Cosac Naify, 2005.

MEYRAN, R. La douleur: emergence et transformation d' un concept. Siences Humaines. Hors Série, n. 48, p. 92-4, mars-avril-mai 2005.

MONTAigne, M. Ensaios. São Paulo: Abril Cultural, 1980 (Col. Os Pensadores).

NEGRI, A.; HARDT, M. O trabalho de Dioniso. Para crítica ao Estado pós-moderno. Juiz de Fora: Pazulin, 2004.

NIETZSCHE, F. Genealogia da moral. São Paulo: Brasiliense, 1988.

SABINO, C. Anabolizantes: drogas de Apolo. In: GOLDENBERG, M. Nu e vestido. Rio de Janeiro: Record, 2002. p. 139-188.

O peso da forma. Cotidiano e uso de drogas entre fisiculturistas. Tese (Doutorado em Ciências Sociais) - Instituto de Filosofia e Ciências Sociais, Universidade Federal do Rio de Janeiro, Rio de Janeiro, 2004.

. O surgimento do bodybuilding. In: LUZ, M.T.; BARROS, N.F. (orgs.). Racionalidades médicas e práticas integrativas em saúde. Estudos teóricos e empíricos. Rio de Janeiro: Cepesc, 2012. p. 357-396. 
SABINO, C.; LUZ, M.T. Espelho da alma. Teoria social e subjetivação em um conto de Machado de Assis. Physis: Revista de Saúde Coletiva. Rio de Janeiro, v. 2, n. 1, p. 237-250, 2011. SEGALEN, M. Ritos e rituais contemporâneos. Rio de Janeiro: FGV, 2002.

TAMBIAH, S. Leveling crowds. Ethononationalist cconflicts and collective violence in south Asia. Los Angeles: University of California Press, 1997.

TURNER, V. O processo ritual. Petrópolis: Vozes, 1974.

VEYNE, P. Foucault. Seu pensamento, sua pessoa. Rio de Janeiro: Civilização Brasileira, 2011.

VINCENT, G. O corpo e o enigma sexual. In: ARIÈS, P.; DUBY, G. (orgs.). História da vida privada. v. 5 5. São Paulo: Companhia das Letras, 1992.

WACQUANT, L. Corpo e alma. Notas etnográficas de um aprendiz de boxe. Rio de Janeiro: Relume-Dumará, 2002.

\section{Notas}

1 "Marombeiros", como se autodefinem, são os fisiculturistas e/ou praticantes veteranos de musculação que ostentam forma física com musculatura consideravelmente acima da média. A palavra deriva de maromba, vara ou barra que o funâmbulo usa para se equilibrar na maroma, que vem a ser a corda na qual caminha. Maromba pode também estar relacionada ao peso com o qual o funâmbulo se mantém em equilíbrio. Como no fisiculturismo e halterofilismo são utilizadas barras com pesos (halteres) removíveis nas extremidades, não é difícil perceber a associação da imagem do homem que anda na corda bamba, utilizando peso para se equilibrar, e daquele que utiliza pesos para aprimorar sua forma e construir sua identidade social (SABINO, 2002). Mais ainda, este aspecto relacionado aos espetáculos circenses sublinha a origem circense do fisiculturismo e halterofilismo nos espetáculos ou freak shows, circo de horrores no século XIX (SABINO, 2012).

${ }^{2}$ Até a década de 20 do século XX, a dor apresentava papel diverso daquele que passou a apresentar posteriormente com a crescente apologia do conforto inerente à sociedade de consumo. Com o surgimento de substâncias para controlar a dor, esta foi relegada a uma dimensão exígua da realidade: "A dor física pertencia à vida cotidiana, e não era vista como uma falha da medicina. Consumia-se uma quantidade muito menor de analgésicos do que hoje em dia, e as pessoas, bem ou mal, se acostumavam a suas insônias sem recorrer a soníferos" (VINCENT, 1992, p. 324).

${ }^{3}$ Um bom exemplo de como se processa essa lógica universal é o trabalho artístico denominado patchwork, que consiste no corte de retalhos de tecidos em forma geométrica, advindos de outros conjuntos e formando elementos recombinados que produzem uma nova forma ou sistema diferente dos anteriores dos quais os elementos foram retirados. Importante relembrar a tradução da palavra: "trabalho com retalho".

${ }^{4}$ A suspensão por ganchos cravados na pele era parte de rituais de iniciação de tribos da América do Norte, o bungee-jump, saltar de alturas elevadas tendo os pés presos por uma corda elástica era praticado pelos nativos da Oceania que prendiam os pés com cipós, as escarificaçôes pertenciam aos rituais de determinadas tribos africanas, a prática do piercing está relacionada aos rituais ameríndios. Práticas similares adotadas pelos grupos das grandes cidades remetem aos estudos de Maffesoli sobre 
a proxemia volátil que ocorre nos grandes centros mundiais nos quais se formam tribos urbanas, não raro com configurações efêmeras, organizadas em torno da construção de identidades calcada na articulação de vários símbolos e práticas específicas, em geral absorvidas de outros contextos. Tal processo é denominado pelo autor de neotribalismo (MAFFESOLI, 1987; 1996; BAUMAN, 2004).

${ }^{5}$ C. Sabino participou na concepção e elaboração do artigo. M.T. Luz realizou a revisão crítica e na revisão bibliográfica. 
Form of pain and pain shape: meaning and function of physical pain among bodybuilding practitioners in gyms in the city of Rio de Janeiro We seek to highlight the meanings of pain for practitioners of bodybuilding gyms in the city of Rio de Janeiro. Eight academies between the northern and southern areas of the city were investigated for 12 months (2008-2009) using participants, ethnographic observations and open interviews, in addition to the data collected in the previous survey period. The construction of the body in this group is related to the organization and administration of intensity and type of pain perceived and interpreted by athletes or assiduous practitioners, a fact related to the rituals of institution building one bodybuilder. The bodily pain is therefore not only parameter for the effective construction of form, but fundamental to hierarchical demarcation of roles and identity of those who are part of the dominant fraction in the field of bodybuilding. It is also, for some individuals, a strategy to overcome suffering.

> Key words: pain; suffering; bodybuilding; strength training; body anthropology. 